\title{
Análisis comparativo entre la segunda Carta de Derechos norteamericana y la Constitución mexicana en materia de derechos sociales
}

Comparative analysis between the second North American Bill of Rights and the Mexican Constitution in the field of social rights

Autor: José Fernando Vázquez Avedillo

DOI: http://doi.org/10.25058/1794600X.1791

\footnotetext{
SP MISIÓN JURÍDICA A 


\title{
ANÁLISIS COMPARATIVO ENTRE LA SEGUNDA CARTA DE DERECHOS NORTEAMERICANA Y LA CONSTITUCIÓN MEXICANA EN MATERIA DE DERECHOS SOCIALES*
}

\author{
Comparative analysis between the second North American Bill of \\ Rights and the Mexican Constitution in the field of social rights \\ Análise comparativa entre a segunda Declaração de Direitos da \\ América do Norte e a Constituição Mexicana sobre direitos sociais
}

José Fernando Vázquez Avedillo ${ }^{a}$

fvaasesoria@gmail.com

Fecha de recepción: 19 de marzo de 2020 Fecha de revisión: 21 de marzo de 2020

Fecha de aceptación: 24 de marzo de 2020

Para citar este artículo:

Vázquez Avedillo, J. F (2020). Análisis comparativo entre la segunda Carta de Derechos norteamericana y la Constitución mexicana en materia de derechos sociales. Revista Misión Jurídica, 13, (19), 144- 157.

\section{RESUMEN}

Los derechos sociales son un elemento medular de los derechos humanos, y su adopción, reconocimiento y protección varían de país en país. El presente trabajo expondrá un muy breve análisis comparativo entre la forma en que se conciben dichos derechos en los Estados Unidos de América y en México, a efecto de desentrañar el tema de la eficacia en su aplicación en cada país.

\footnotetext{
* Artículo de reflexión.

a. Doctor en Derecho, Profesor Investigador de tiempo completo, integrante del Cuerpo Académico "Derechos Humanos y Globalización", de la Facultad de Derecho de la Universidad Autónoma de Querétaro. Perfil Deseable PRODEP y miembro del Sistema Nacional de Investigadores (SNI I). ORCID: https://orcid.org/0000-0002-2522-142X Se agradece la colaboración para este proyecto de la Dra. Alina del Carmen Nettel Barrera, integrante del Cuerpo Académico antes citado.
} 


\section{PALABRAS CLAVES}

Derechos sociales; derechos humanos; eficacia.

\section{ABSTRACT}

Social rights are a core element of Human Rights and their adoption, recognition and protection vary from country to country. The present investigation will explain in a very brief comparative analysis the way in which these rights are conceived in the United States of America and in Mexico, with the purpose of untangling the subject of their effective implementation in each country.

\section{KEY WORDS}

Social rights; Human Rights; efficiency.

\section{RESUMO}

Os direitos sociais são um elemento central dos direitos humanos e sua adoção, reconhecimento e proteção variam de país para país. Este trabalho apresentará uma análise comparativa muito breve entre a forma como esses direitos são concebidos nos Estados Unidos da América e no México, a fim de desvendar a questão da eficácia de sua aplicação em cada país.

\section{PALAVRAS-CHAVES}

Direitos sociais; direitos humanos; eficácia.

\section{INTRODUCCIÓN}

Uno de los elementos que muestran el grado de compromiso gubernamental con la protección y cuidado de su población está vinculado al grado de respeto de los derechos humanos y particularmente de los derechos sociales.

En esta ocasión se pretende realizar un ejercicio comparativo entre la forma en que se protegen los derechos sociales en México y lo que acontece con nuestro vecino del norte, es decir, con lo Estados Unidos de América, a efecto de establecer hasta donde llega el grado de compromiso en cada caso, y desde luego, su grado de justiciabilidad y de eficacia al momento de un reclamo por parte de un particular.

El análisis partirá para el caso mexicano, de la Constitución Política y desde luego de los tratados internacionales signado por el país; y en el caso norteamericano, se utilizará su Constitución y la segunda Carta de Derechos.

Debemos puntualizar que la utilización del Pacto Internacional de Derechos Económicos, Sociales y Culturales será una herramienta de vital importancia para análisis que se plantea.

Aunque hay que partir del hecho de que se trata de sistemas jurídicos y condiciones generales diferentes, se tratará de hacer ese ejercicio ponderativo para calificar el grado de eficacia, que es lo que al final del camino reclama una persona o grupo de personas pertenecientes a un Estado.

\section{LOS DERECHOS SOCIALES}

Una primera tarea a desarrollar consiste en dejar en claro lo que significan los derechos sociales y señalar el alcance de los mismos respecto de la esfera jurídica de las personas "Hoy en día se reconoce a los derechos sociales fundamentales carácter de derechos subjetivos, siendo su objeto prestaciones positivas fácticas del Estado, entre ellas la alimentación, la salud, la educación, el trabajo, la vivienda y la seguridad social" (Arango, 2015: 1677).

En este sentido, Gerardo Pisarello hace también referencia a esa idea de satisfacer necesidades básicas de las personas: "Habitualmente, los derechos sociales se presentan como expectativas ligadas a la satisfacción de necesidades básicas de las personas en ámbitos como el trabajo, la vivienda, la salud, la alimentación o la educación" (Pisarello, 2007: 11).

Partiendo de lo anterior, podemos señalar que los derechos sociales son aquellos derechos subjetivos que ayudan a las personas a desarrollarse en un ámbito de autonomía, igualdad y libertad, permitiéndoles contar con ciertas condiciones para acceder a una vida digna, entendiendo ésta como un "conjunto de condiciones que permiten preservar la integridad física y psíquica y minimizar, en consecuencia, las situaciones de malestar, daño y opresión" (Pisarello, 2007: 39)

Las anteriores características proporcionadas por Pisarello, nos llevan a la idea de que los 
derechos sociales se encuentran principalmente vinculados a clases sociales vulnerables.

Es el conjunto de normas jurídicas que establecen y desarrollan diferentes principios y procedimientos protectores a favor de las personas, grupos y sectores de la sociedad integrados por individuos socialmente débiles, para lograr su convivencia con otras clases sociales, dentro de un orden jurídico. (Gaxiola, 2004: 367)

No hay duda que los derechos sociales forman parte de lo que llamamos genéricamente como derechos humanos y de manera específica han sido ubicados en el grupo de los derechos económicos, sociales, culturales y ambientales (DESCA), mismos que se encuentran reconocidos por nuestra Constitución, y además se encuentran considerados y regulados desde la Declaración Universal de los Derechos Humanos del año 1948 y desde luego, en el Pacto Internacional de Derechos Económicos, Sociales y Culturales (PIDESC), que data de 1966, aunque con entrada en vigencia solo hasta 1976.

Debemos señalar que los derechos sociales no son cosa nueva, pues la historia de los mismos se remonta a épocas pretéritas, destacándose particularmente con la aparición del constitucionalismo social que data del siglo XIX, sin que esto haga olvidar los antecedentes del siglo XVIII con el movimiento anti absolutista en Europa. En el antiguo continente el constitucionalismo aparece para limitar el ejercicio del poder, teniendo como basamento filosófico el iusnaturalismo racionalista y de forma particular a las teorías de John Locke y Jean Jaques Rousseau; siendo este último uno de los ideólogos de la revolución francesa, de donde derivará la Declaración de los Derechos del Hombre y del Ciudadano de 1789 que, junto con los acontecimientos previos en las colonias inglesas en América (Declaración de Virginia de 1776 y la Constitución de los Estados Unidos de Norteamérica de 1787), generarían grandes cambios para toda la humanidad.

En el siglo XVIII la ayuda o el apoyo a pobres, niños o ancianos ex- pósitos era asunto librado a la familia o la beneficencia pública y priva- da en forma de deberes jurídicos o morales. En el siglo XIX los derechos sociales se identificaron con demandas que, mediante luchas políticas y sociales, podían lograr el status de derechos legales de grupos particulares, como en el caso de los trabajadores asalariados. En el siglo XX les fue dado el carácter de fines u objetivos sociales para cuya realización se requiere de normas jurídicas que impongan obligaciones positivas a las autoridades públicas, lo cual excluía la posibilidad individual de hacerlos exigibles directamente ante los jueces. Hoy en día los derechos sociales son entendidos por una amplia corriente doctrinaria como verdaderos derechos humanos y fundamentales a nivel internacional y en diversas constituciones nacionales. (Arango, 2015:1678-1679)

El constitucionalismo social está claramente determinado a partir de la Constitución francesa de 1848, que estableció una serie de deberes estatales, referidos puntualmente a la protección de los ciudadanos en dos temas torales: el trabajo y la educación, entendidos estos como la vía para alcanzar un mejor nivel de vida.

VIII. - La República debe proteger al ciudadano en su persona, su familia, su religión, su propiedad, su trabajo, y poner al alcance de cada cual la instrucción indispensable a todos los hombres; debe, mediante una asistencia fraterna, asegurar la subsistencia de los ciudadanos necesitados, ya sea procurándoles trabajo en los límites de sus recursos, ya sea socorriendo, a falta de la familia, a aquellos que no están en estado de poder trabajar. - Para conseguir el cumplimiento de todos estos deberes y para garantizar todos estos derechos, la Asamblea nacional, fiel a las tradiciones de las grandes asambleas que han inaugurado la Revolución francesa, decreta, tal como sigue, la Constitución de la República.

Art. 13.- La Constitución garantiza a los ciudadanos la libertad de trabajo y de industria. La sociedad favorece y anima el desarrollo del trabajo mediante la enseñanza primaria gratuita, la educación profesional, la igualdad en las relaciones entre el patrón y el obrero, las instituciones de prevención y de crédito, las instituciones agrícolas, las asociaciones voluntarias, y el establecimiento, por parte del estado, los departamentos y los municipios, de trabajos públicos propios para el empleo de los brazos sin ocupación; proporciona asistencia a los niños abandonados, a los impedidos y a los 
ancianos sin recursos, y a quienes sus familias no puedan socorrer (Constitución de Francia, 1848).

El ejemplo de la Constitución francesa de 1848 impregnó el espíritu de muchos países (García Pérez, 2013: 59), en donde poco a poco se fueron gestando documentos constitucionales de carácter social, tal y como sucedió con México, siendo nuestro país, referente para el nacimiento de otras constituciones con características semejantes.

$\mathrm{Si}$ bien las revoluciones de principios del siglo XX dieron un apreciable empuje al desarrollo del derecho laboral, comunitario, solidario y de seguridad social, los derechos sociales no obtuvieron un estatus de derechos fundamentales a la par con los derechos de libertad. Esto en buena medida por la deficiente institucionalización de mecanismos judiciales para la protección constitucional de los derechos fundamentales. Los derechos sociales continuaron siendo objeto de la política legislativa y su conquista fruto de las luchas políticas (Arango 2015: 1680-1681).

La evolución del constitucionalismo a nivel mundial, se ve reflejado claramente en el sentido que la Constitución mexicana de 1917 tuvo con respecto a proteger a sectores vulnerables de la población. En esta tesitura, resulta trascendente recordar que la Constitución Política de los Estados Unidos Mexicanos, promulgada el 5 de febrero de 1917, fue pionera en materia de derechos sociales, particularmente por el sentido que se le dio respecto de dos sectores específicos de la población, el campesino y el obrero, circunstancia que sirvió de base para el desarrollo de dichos derechos a lo largo y ancho de todo el orbe.

Sin duda alguna, los derechos sociales son derechos humanos que en muchas ocasiones se han visto empañados ante la imposibilidad fáctica de su aplicación generalizada en las poblaciones de muchos países, muy a pesar de existir sendos referentes en instrumentos internacionales, que no en todos los casos son aplicables.

A continuación, daremos cabida a analizar el caso específico de los Estados Unidos de Norteamérica y cómo es que se han visualizado los derechos sociales en esa latitud.

\section{LOS DERECHOS SOCIALES EN LOS ESTADOS UNIDOS DE NORTEAMÉRICA}

Para desarrollar este apartado será menester acudir a la Constitución norteamericana, su primera carta de derechos (Bill of Rights) y desde luego la segunda carta de derechos.

Dicho lo anterior, comenzaremos por describir la Constitución norteamericana, la cual fue aprobada el 17 de septiembre de 1787, teniendo originalmente siete artículos, en los cuales no existía el pronunciamiento respecto a cualquier tipo de derecho tendiente a proteger a las personas, pues básicamente dicha Constitución era de carácter orgánico.

Para el 15 de diciembre de 1791 fueron ratificadas las diez primeras enmiendas a la Constitución, las cuales son conocidas comúnmente como la Carta de Derechos (Bill of Rights).

Esta Carta de derechos fue influenciada por la Declaración de Derechos de Virginia, diseñada por George Mason en 1776, instrumento legal de gran calado que incluso influenciaría en la redacción de la Declaración de los Derechos del Hombre y del Ciudadano, producto de la Revolución francesa de 1789.

A continuación, nos referiremos a las diez primeras enmiendas de la Constitución norteamericana.

Enmienda I. El Congreso no hará ley alguna por la que adopte una religión como oficial del Estado o se prohíba practicarla libremente, o que coarte la libertad de palabra o de imprenta, o el derecho del pueblo para reunirse pacíficamente y para pedir al gobierno la reparación de agravios.

Enmienda II. Siendo necesaria una milicia bien ordenada para la seguridad de un Estado Libre, no se violará el derecho del pueblo a poseer y portar armas.

Enmienda III. En tiempo de paz a ningún militar se le alojará en casa alguna sin el consentimiento del propietario; ni en tiempo de guerra, como no sea en la forma que prescriba la ley.

Enmienda IV. El derecho de los habitantes de que sus personas, domicilios, papeles $\mathrm{y}$ efectos se hallen a salvo de pesquisas $\mathrm{y}$ aprehensiones arbitrarias, será inviolable, y 
no se expedirán al efecto mandamientos que no se apoyen en un motivo verosímil, estén corroborados mediante juramento o protesta y describan con particularidad el lugar que deba ser registrado y las personas o cosas que han de ser detenidas o embargadas.

Enmienda V. Nadie estará obligado a responder de un delito castigado con la pena capital o con otra infamante si un gran jurado no lo denuncia o acusa, a excepción de los casos que se presenten en las fuerzas de mar o tierra o en la milicia nacional cuando se encuentre en servicio efectivo en tiempo de guerra o peligro público; tampoco se pondrá a persona alguna dos veces en peligro de perder la vida o algún miembro con motivo del mismo delito; ni se le compelerá a declarar contra sí misma en ningún juicio criminal; ni se le privará de la vida, la libertad o la propiedad sin el debido proceso legal; ni se ocupará la propiedad privada para uso público sin una justa indemnización.

Enmienda VI. En toda causa criminal, el acusado gozará del derecho de ser juzgado rápidamente $\mathrm{y}$ en público por un jurado imparcial del distrito y Estado en que el delito se haya cometido, Distrito que deberá haber sido determinado previamente por la ley; así como de que se le haga saber la naturaleza y causa de la acusación, de que se le caree con los testigos que depongan en su contra, de que se obligue a comparecer a los testigos que le favorezcan y de contar con la ayuda de un abogado que lo defienda.

Enmienda VII. El derecho a que se ventilen ante un jurado los juicios de derecho consuetudinario en que el valor que se discuta exceda de veinte dólares, será garantizado, y ningún hecho de que haya conocido un jurado será objeto de nuevo examen en tribunal alguno de los Estados Unidos, como no sea con arreglo a las normas del derecho consuetudinario.

Enmienda VIII. No se exigirán fianzas excesivas, ni se impondrán multas excesivas, ni se infligirán penas crueles y desusadas.

Enmienda IX. No por el hecho de que la Constitución enumera ciertos derechos ha de entenderse que niega o menosprecia otros que retiene el pueblo.

Enmienda X. Los poderes que la Constitución no delega a los Estados Unidos ni prohíbe a los Estados, queda reservados a los Estados respectivamente 0 al pueblo (National Archives, 2019).

Con el tiempo, se fueron agregando otras enmiendas, sin embargo, el sentido fue el mismo, pues no se tocó el tema de los derechos sociales de las personas.

TABLA 1. RESUMEN DE LAS ENMIENDAS CONSTITUCIONALES POSTERIORES A LA PRIMERA CARTA DE DERECHOS

\begin{tabular}{|l|l|l|}
\hline \multicolumn{1}{|c|}{ NO. } & \multicolumn{1}{|c|}{ CONTENIDO DE LA ENMIENDA } & \multicolumn{1}{|c|}{ FECHA DE } \\
PROMULGACIÓN
\end{tabular}




\begin{tabular}{|l|l|l|}
\hline \multicolumn{1}{|c|}{ NO. } & \multicolumn{1}{|c|}{ CONTENIDO DE LA ENMIENDA } & \multicolumn{1}{c|}{ FECHA DE } \\
\hline Enmienda XIX & Derecho de sufragio femenino. & $($ agosto 18, 1920) \\
\hline Enmienda XX & $\begin{array}{l}\text { Inicio del período del congreso (3 de enero) y del presidente } \\
\text { (20 de enero) }\end{array}$ & $($ enero 23, 1933) \\
\hline Enmienda XXI & $\begin{array}{l}\text { Derogación de la XVIII Enmienda; se permite que cada estado } \\
\text { localidad establezca sus propias leyes sobre alcohol (leyes } \\
\text { secas). }\end{array}$ & $($ diciembre 5, 1933) \\
\hline Enmienda XXII & Limitación de la elección del presidente a dos períodos. & $($ febrero 27, 1951) \\
\hline Enmienda XXIII & Representación de Washington D. C. en el colegio electoral. & (marzo 29, 1961) \\
\hline Enmienda XXIV & $\begin{array}{l}\text { Prohibición de condicionar el voto al pago de impuestos electo- } \\
\text { rales o de cualquier tipo. }\end{array}$ & $($ enero 23, 1964) \\
\hline Enmienda XXV & $\begin{array}{l}\text { Procedimiento ante situaciones de incapacidades } \\
\text { presidenciales. }\end{array}$ & (febrero 10, 1967) \\
\hline Enmienda XXVI & Derecho de sufragio universal a la edad de 18 años. & $(1$ julio, 1971) \\
\hline Enmienda XXVII & Variación de la remuneración de los miembros del congreso. & (mayo 7, 1992) \\
\hline
\end{tabular}

Fuente: Elaboración propia con datos de National Archives, 2019.

Como se puede observar, dichas enmiendas, es decir, la primera Carta de Derechos y las enmiendas constitucionales posteriores hasta el año de 1992, solamente aportaron lo que conocemos como derechos civiles y políticos, pero nada en específico respecto de derechos sociales. Desde luego, estas enmiendas y particularmente la IX y la X, dan pauta -mediante la interpretacióna la existencia de otros derechos, sin embargo, en ese momento concreto no hubo un pronunciamiento específico respecto del tema, dejando las cosas en manos de la Corte, la cual a través del tiempo ha hecho su trabajo, ampliando o restringiendo derechos.

De forma particular podemos afirmar que la Carta de Derechos, en realidad no impactó judicialmente durante los primeros 150 años de su existencia, sin embargo, también podemos decir que ha sido el cimiento de muchas de las decisiones de la Corte Suprema norteamericana a partir del siglo XX.

\section{EL NEW DEAL Y LA SEGUNDA CARTA DE DERECHOS}

El New Deal fue la denominación dada a un conjunto de programas y proyectos instituidos por el entonces presidente de los Estados Unidos Franklin Delano Roosevelt, como parte de su política intervencionista motivada por la Gran
Depresión que su país experimentaba y con la firme intención de estabilizar la economía nacional.

En el año de 1941, y como resultado del New Deal, Roosevelt, dio un discurso mediante el cual propuso cuatro libertades básicas:

1. Libertad de expresión;

2. Libertad de culto;

3. Libertad para vivir sin miseria;

4. Libertad para vivir sin temor.

Estas libertades a las que se refería Roosevelt darían pauta a lo que hoy se conoce como la segunda Carta de Derechos de los Estados Unidos de Norteamérica.

Derivado de esto, el propio Roosevelt enumeró una serie de derechos que darían una fisonomía totalmente diferente a la visión liberal que se tenía en los Estados Unidos.

- El derecho a un trabajo útil y remunerado en la industria, el comercio, la agricultura o las minas de la nación;

- El derecho a ganar lo suficiente para tener alimentación, ropa y recreación adecuadas;

- El derecho de cada agricultor a cultivar y vender sus productos y obtener una ganancia que les dé, a él y a su familia, una vida decente; 
- El derecho de todo empresario, grande o pequeño, a comerciar en un ambiente libre de competencia desleal y del dominio de monopolios nacionales o extranjeros;

- El derecho de toda familia a un hogar decente;

- El derecho a recibir atención médica adecuada y la oportunidad de lograr y disfrutar de una buena salud;

- El derecho a una protección adecuada contra los temores económicos de la vejez, la enfermedad, los accidentes y el desempleo;

- El derecho a una buena educación (Sustein, 2018: 30-319).

En este sentido, el propio Roosevelt señaló que este conjunto de derechos a los que se refirió, tenían como propósito fundamental brindar un espectro de seguridad a las personas, razón por lo que solicitó al Congreso norteamericano explorar los medios necesarios para su implementación, sin que esto tuviera el resultado que el presidente esperaba, pues esta segunda carta de derechos no impacto directamente en la Constitución; de hecho, el resultado más tangible fue la emisión de una ley, la Ley del soldado, "que ofrecía una serie de beneficios de vivienda, de atención médica, de educación y de capacitación a los veteranos de guerra que regresaban" (Kennedy, 1999: 786-787).

La segunda carta de derechos estaba destinada a garantizar la materialización de la libertad para vivir sin miseria, lo que, para Roosevelt, implicaba "acuerdos económicos que asegurarán a todas las naciones del mundo una vida saludable y de paz para sus habitantes." (Sustein 2018:20).

Cass Sustein llama a esta segunda carta de derechos como compromisos constitutivos, ya que contribuyen a crear valores básicos de una sociedad, derivando de esto que no exista una necesidad imperiosa de ser positivizados, circunstancia de donde proviene que los derechos constitucionales pudiesen ser considerados como un subconjunto de compromisos constitutivos (Sustein, 2018: 77-79).

Bajo esta premisa, partiríamos de la idea de que esos derechos sociales que, aunque no están plasmados en un texto legal, resultan de tal forma que deben ser considerados para proteger a las personas, particularmente a aquellas envueltas en vulnerabilidad.

Derivado de lo anterior, ha tenido que ser la Corte norteamericana la que de vez en vez tenga que pronunciarse respecto de la defensa de los derechos sociales, resolviendo caso por caso, circunstancia que ha sido el punto de inflexión ya que, dependiendo de la composición de los miembros de la Corte, ha sido la tendencia hacia la mayor o menor protección de los derechos multicitados.

(...) lo que la Corte ha hecho es tratar a los derechos constitucionales no como reglas rígidas establecidas de modo definitivo, sino como principios generales que pueden crecer y cambiar con el tiempo (Sustein, 2018: 164).

Una etapa peculiar en la impartición de justicia en los Estados Unidos fue precisamente la que se dio bajo la presidencia de Richard Nixon, quien en su idea de restablecer la ley y el orden, en 1968 designó cuatro jueces a la Suprema Corte de Justicia (Warren Earl Burger, Harry Blackmun, Lewis Powell y William Hubbs Rehnquist), los cuales fueron factor determinante para que esa segunda carta de derechos no llegara a ser parte del texto constitucional y desde luego, sus interpretaciones fueron en el sentido de restringir esos derechos a los peticionarios.

De lo anterior, queda de manifiesto que el presidente de los Estados Unidos es un factor determinante en la composición de la Corte Suprema y, con ello, puede entenderse la tendencia que este órgano jurisdiccional vaya teniendo en el manejo de los derechos sociales en este país, destacándose una clara inclinación hacia el conservadurismo, lo cual choca con la idea de la aplicación de derechos sociales.

The Federalist Society for Law and Public Policy Studies (tal es su nombre completo) defiende una concepción llamada "originalista". Privilegia una teoría de interpretación jurídica apegada a lo que la Carta Magna quiso decir en el momento de su aplicación en 1789. Su corolario es el "textualismo", que antepone como interpretación lo que se dijo directamente en la Constitución en vez de una interpretación de la intención del legislador. De este modo, se le atribuye al texto fundamental un carácter 
restringido claro, evidente y unívoco del que la justicia no debe apartarse (Schapire, 2018, s.p.)

\section{ANÁLISIS DE LOS DERECHOS SOCIALES NORTEAMERICANOS Y MEXICANOS}

A continuación, procederemos a realizar un marco comparativo entre los derechos sociales previstos en la denominada segunda carta de derechos norteamericana y lo contenido en la Constitución Política de los Estados Unidos Mexicanos.

Resulta por demás importante hacer notar que, mientras la Constitución mexicana y varios tratados internacionales de los que nuestro país es parte, nos constriñen a buscar por todos los medios la satisfacción de los derechos sociales de los mexicanos, en el caso norteamericano, la normativa que analizaremos, es decir, la segunda carta de derechos, solamente funciona como un referente para los jueces a efecto de que, dependiendo de su perfil -conservador o liberalestos tomarán decisiones que impactarán en los peticionarios de justicia.

Dicho lo anterior, comenzaremos por citar el derecho señalado por la segunda carta norteamericana y enseguida su correspondencia desde nuestra Carta Magna.

\section{a) El derecho a un trabajo útil y remunerado en la industria, el comercio, la agricultura o las minas de la nación}

En este sentido, nuestra Carta Magna instituye hoy de forma directa el derecho a un trabajo remunerado, estableciéndose para el caso una serie de mecanismos para proteger la dignidad de la persona del trabajador, circunstancia que queda prevista en los artículos 5 y 123.

Artículo 5o. A ninguna persona podrá impedirse que se dedique a la profesión, industria, comercio o trabajo que le acomode, siendo lícitos. El ejercicio de esta libertad sólo podrá vedarse por determinación judicial, cuando se ataquen los derechos de tercero, o por resolución gubernativa, dictada en los términos que marque la ley, cuando se ofendan los derechos de la sociedad. Nadie puede ser privado del producto de su trabajo, sino por resolución judicial (...)
Nadie podrá ser obligado a prestar trabajos personales sin la justa retribución y sin su pleno consentimiento, salvo el trabajo impuesto como pena por la autoridad judicial, el cual se ajustará a lo dispuesto en las fracciones I y II del artículo 123 (...)

Artículo 123. Toda persona tiene derecho al trabajo digno y socialmente útil; al efecto, se promoverán la creación de empleos y la organización social de trabajo, conforme a la ley (CPEUM 2020).

Ya desde la promulgación de la Constitución mexicana en 1917, había quedado patente esa intención del constituyente de proteger a las clases sociales vulnerables, como es el caso de la clase trabajadora, circunstancia que ha venido fortaleciéndose a través de los años, ampliando esos derechos con el paso del tiempo.

Ahora bien, por si esto no fuera suficiente, el Pacto Internacional de Derechos Económicos, Sociales y Culturales (Pidesc), del cual México es parte, también impone obligaciones al gobierno para garantizar el derecho al trabajo.

Artículo 6

1. Los Estados Partes en el presente Pacto reconocen el derecho a trabajar, que comprende el derecho de toda persona a tener la oportunidad de ganarse la vida mediante un trabajo libremente escogido o aceptado, y tomarán medidas adecuadas para garantizar este derecho. (PIDESC 2020)

\section{Artículo 7}

Los Estados Partes en el presente Pacto reconocen el derecho de toda persona al goce de condiciones de trabajo equitativas $y$ satisfactorias que le aseguren en especial:

a) Una remuneración que proporcione como mínimo a todos los trabajadores:

i) Un salario equitativo e igual por trabajo de igual valor, sin distinciones de ninguna especie; en particular, debe asegurarse a las mujeres condiciones de trabajo no inferiores a las de los hombres, con salario igual por trabajo igual; (...) (PIDESC 2020).

\section{b) El derecho a ganar lo suficiente para tener alimentación, ropa y recreación adecuadas}


En este sentido, es de reiterarse el comentario anterior, ya que el esquema protector de la Constitución mexicana refiere que todo trabajo debe ser justamente retribuido, de manera que permita a las personas alcanzar un nivel de vida digno, tal y como lo expresa el artículo primero constitucional y los artículos 6 y 7 del Pidesc.

\section{c) El derecho de cada agricultor a cultivar $y$ vender sus productos y obtener una ganancia que les dé, a él y a su familia, una vida decente}

Aunque este derecho norteamericano hace una referencia específica al sector campesino, su sentido sigue siendo en pro de una libertad de actuación en términos laborales que posibilite la salvaguarda del trabajador y su familia a efecto de alcanzar un grado de dignidad en su vida. Circunstancia que, como ya se mencionó en párrafos anteriores, se encuentra plenamente prevista en nuestro texto constitucional, tanto en el artículo 5ํㅜ, como en el 123.

Artículo 5o. A ninguna persona podrá impedirse que se dedique a la profesión, industria, comercio o trabajo que le acomode, siendo lícitos. El ejercicio de esta libertad sólo podrá vedarse por determinación judicial, cuando se ataquen los derechos de tercero, o por resolución gubernativa, dictada en los términos que marque la ley, cuando se ofendan los derechos de la sociedad. Nadie puede ser privado del producto de su trabajo, sino por resolución judicial (...) (CPEUM 2020).

Nuevamente, los artículos 6 y 7 del Pidesc cobran vigencia para efecto del caso mexicano pues refuerzan la idea de que toda persona pueda dedicarse al empleo o trabajo lícito que le permita mantener un status de dignidad para él y su familia.

\section{d) El derecho de todo empresario, grande o pequeño, a comerciar en un ambiente libre de competencia desleal y del dominio de monopolios nacionales o extranjeros}

En este caso, este derecho norteamericano lo encontramos presente bajo el tema de la libre competencia que nos anuncia el artículo 28 constitucional, el cual refiere lo siguiente:
Artículo 28. En los Estados Unidos Mexicanos quedan prohibidos los monopolios, las prácticas monopólicas, los estancos y las exenciones de impuestos en los términos y condiciones que fijan las leyes. El mismo tratamiento se dará a las prohibiciones a título de protección a la industria...

El Estado contará con una Comisión Federal de Competencia Económica, que será un órgano autónomo, con personalidad jurídica y patrimonio propio, que tendrá por objeto garantizar la libre competencia y concurrencia, así como prevenir, investigar y combatir los monopolios, las prácticas monopólicas, las concentraciones y demás restricciones al funcionamiento eficiente de los mercados, en los términos que establecen esta Constitución y las leyes. La Comisión contará con las facultades necesarias para cumplir eficazmente con su objeto, entre ellas las de ordenar medidas para eliminar las barreras a la competencia y la libre concurrencia; regular el acceso a insumos esenciales, y ordenar la desincorporación de activos, derechos, partes sociales o acciones de los agentes económicos, en las proporciones necesarias para eliminar efectos anticompetitivos (...) (CPEUM 2020).

De manera particular, el gobierno mexicano cuenta con un órgano específico para garantizar la libre competencia, mismo que por disposición constitucional se le otorga autonomía técnica y funcional, circunstancia que lo pone a salvo de los embates que pudiesen venir de las funciones tradicionales del poder público, es decir, el Ejecutivo, el Legislativo y el Judicial.

Para este caso, el Pidesc no hace una precisión exacta del tema de la libre competencia, sin embargo, este factor resulta determinante para lograr satisfacer los derechos sociales de las clases vulnerables, así que resulta aplicable el artículo 2 , como medida de garantía en el cumplimiento de sus obligaciones.

Artículo 2

1. Cada uno de los Estados Partes en el presente Pacto se compromete a adoptar medidas, tanto por separado como mediante la asistencia y la cooperación internacionales, especialmente económicas y técnicas, hasta el máximo de los recursos de que disponga, para lograr progresivamente, por todos los 
medios apropiados, inclusive en particular la adopción de medidas legislativas, la plena efectividad de los derechos aquí reconocidos.

2. Los Estados Partes en el presente Pacto se comprometen a garantizar el ejercicio de los derechos que en él se enuncian, sin discriminación alguna por motivos de raza, color, sexo, idioma, religión, opinión política o de otra índole, origen nacional o social, posición económica, nacimiento o cualquier otra condición social.

3. Los países en desarrollo, teniendo debidamente en cuenta los derechos humanos y su economía nacional, podrán determinar en qué medida garantizarán los derechos económicos reconocidos en el presente Pacto a personas que no sean nacionales suyos. (PIDESC 2020)

\section{e) El derecho de toda familia a un hogar decente}

Si bien es cierto el término utilizado por Roosevelt para adjetivar a la palabra hogar, pudiéramos considerarlo como el menos afortunado, queda claro que la intención estaba direccionada a señalar el tema de la dignidad de la persona, es decir, hacer referencia a una vivienda digna, tal y como nuestra Carta Magna lo señala en su artículo 4ํㅡㄹ el cual indica lo siguiente:

(...) Toda familia tiene derecho a disfrutar de vivienda digna y decorosa. La Ley establecerá los instrumentos y apoyos necesarios a fin de alcanzar tal objetivo (...) (CPEUM 2020).

Es claro que tanto la visión norteamericana como la nuestra, parten de la idea de que una vivienda digna puede ser posibilitadora de otros derechos fundamentales, razón por la que el término de dignidad resulta mayormente afortunado en la redacción de nuestro texto constitucional.

Por si esto no fuese suficiente, el Pidesc también relata dicho derecho, aunque la forma de adjetivarlo también resulte poco clara, ya que se refiere a una vivienda adecuada, circunstancia que raya en la subjetividad del interprete.

\section{Artículo 11}

1. Los Estados Partes en el presente Pacto reconocen el derecho de toda persona a un nivel de vida adecuado para sí y su familia, incluso alimentación, vestido y vivienda adecuados, y a una mejora continua de las condiciones de existencia. Los Estados Partes tomarán medidas apropiadas para asegurar la efectividad de este derecho, reconociendo a este efecto la importancia esencial de la cooperación internacional fundada en el libre consentimiento (PIDESC, 2020).

\section{f) El derecho a recibir atención médica adecuada y la oportunidad de lograr y disfrutar de una buena salud}

El derecho a la salud resulta ser uno de esos derechos, sin los cuales, la esencia de una persona puede desaparecer, razón suficiente para surgir la obligación de garantizar tan vital derecho.

Desde el punto de vista de nuestra Constitución, la idea del derecho a la salud se advierte de varias formas previstas en el artículo $4^{\circ}$, que a la letra señala:

(...) Toda persona tiene derecho a la protección de la salud. La Ley definirá las bases y modalidades para el acceso a los servicios de salud y establecerá la concurrencia de la Federación y las entidades federativas en materia de salubridad general, conforme a lo que dispone la fracción XVI del artículo 73 de esta Constitución.

Toda persona tiene derecho a un medio ambiente sano para su desarrollo y bienestar. El Estado garantizará el respeto a este derecho. El daño y deterioro ambiental generará responsabilidad para quien lo provoque en términos de lo dispuesto por la ley.

Toda persona tiene derecho al acceso, disposición y saneamiento de agua para consumo personal y doméstico en forma suficiente, salubre, aceptable y asequible. El Estado garantizará este derecho y la ley definirá las bases, apoyos y modalidades para el acceso y uso equitativo y sustentable de los recursos hídricos, estableciendo la participación de la Federación, las entidades federativas y los municipios, así como la participación de la ciudadanía para la consecución de dichos fines (...) (CPEUM 2020) 
Como puede apreciarse, el primer párrafo transcrito ofrece una visión general sobre el derecho a la salud, sin embargo, el siguiente párrafo hace mención a que las personas tienen derecho a un medio ambiente sano, elemento que sin duda alguna contribuye decisivamente a la salud de las personas, circunstancia que se ve reforzada con la idea del acceso al agua, como elemento central de la vida de ser humano. Es así que, de forma global, podemos entender ese derecho a la salud desde el punto de vista del derecho mexicano.

Aunado a lo anterior, el Pidesc también refiere el derecho a la salud, señalando incluso medidas que deben adoptar los Estados parte.

Artículo 12

1. Los Estados Partes en el presente Pacto reconocen el derecho de toda persona al disfrute del más alto nivel posible de salud física y mental.

2. Entre las medidas que deberán adoptar los Estados Partes en el Pacto a fin de asegurar la plena efectividad de este derecho, figurarán las necesarias para:

a) La reducción de la mortinatalidad y de la mortalidad infantil, y el sano desarrollo de los niños;

b) El mejoramiento en todos sus aspectos de la higiene del trabajo y del medio ambiente;

c) La prevención y el tratamiento de las enfermedades epidémicas, endémicas, profesionales y de otra índole, y la lucha contra ellas;

d) La creación de condiciones que aseguren a todos asistencia médica y servicios médicos en caso de enfermedad. (PIDESC 2020)

\section{g) El derecho a una protección adecuada contra los temores económicos de la vejez, la enfermedad, los accidentes y el desempleo}

En este caso, en términos generales diríamos que se refiere a lo que se conoce comúnmente como seguridad social, la cual ampara temas como la salud, el bienestar de las personas de la tercera edad, los accidentes de trabajo y el desempleo, temas considerados en nuestra Carta Magna, previsto en los artículos 4 y 123 , principalmente.
De acuerdo con diversos documentos de la Organización Internacional del trabajo (OIT), la seguridad social es:

La seguridad social es la protección que una sociedad proporciona a los individuos y los hogares para asegurar el acceso a la asistencia médica y garantizar la seguridad del ingreso, en particular en caso de vejez, desempleo, enfermedad, invalidez, accidentes del trabajo, maternidad o pérdida del sostén de familia (OIT 2001).

Desde luego hay que señalar que la idea de seguridad social también está considerada en los instrumentos de la Organización de las Naciones Unidas (ONU) como un derecho fundamental, sin que a la fecha este se encuentre universalmente protegido, ya que solo una parte de la población tiene acceso a su disfrute, circunstancia parecida a la que sucede en los Estados Unidos, ya que de acuerdo con la Social Security Act de 1935 y su versión actualizada, el esquema protector se basa en las contribuciones que los trabajadores hacen al sistema, de manera que quien no aporta, queda fuera de su halo protector.

La seguridad social ha sido considerada como un derecho humano básico en la Declaración de Filadelfia de la OIT (1944), y en su Recomendación sobre la Seguridad de los medios de vida, 1944 (Núm. 67). Este derecho está confirmado en la Declaración Universal de los Derechos Humanos, 1948, y en el Pacto Internacional sobre Derechos Económicos, Sociales y Culturales, 1966 (OIT 2001).

\section{h) El derecho a una buena educación}

Este derecho que a todas luces resulta ser de índole fundamental, es considerado por nuestra Constitución, particularmente en el artículo tercero, el cual nos relata lo siguiente:

Artículo 3o. Toda persona tiene derecho a la educación. El Estado -Federación, Estados, Ciudad de México y Municipios- impartirá y garantizará la educación inicial, preescolar, primaria, secundaria, media superior $\mathrm{y}$ superior. La educación inicial, preescolar, primaria y secundaria, conforman la educación básica; ésta y la media superior serán obligatorias, la educación superior lo será en términos de la fracción $\mathrm{X}$ del presente 
artículo. La educación inicial es un derecho de la niñez y será responsabilidad del Estado concientizar sobre su importancia.

La educación se basará en el respeto irrestricto de la dignidad de las personas, con un enfoque de derechos humanos y de igualdad sustantiva. Tenderá a desarrollar armónicamente todas las facultades del ser humano y fomentará en él, a la vez, el amor a la Patria, el respeto a todos los derechos, las libertades, la cultura de paz y la conciencia de la solidaridad internacional, en la independencia y en la justicia; promoverá la honestidad, los valores y la mejora continua del proceso de enseñanza aprendizaje (CPEUM 2020).

En nuestro caso, la descripción constitucional omite adjetivar como buena a la educación que tienen derecho todos los mexicanos, tal y como lo hace la segunda carta de derechos norteamericana, sin embargo, es de esperarse -aunque sea un elemento eminentemente subjetivo- que la educación sea de buena calidad. En este sentido, el segundo párrafo del artículo tercero constitucional podría interpretarse en ese sentido.

Por su parte, el Pidesc, también hace referencia a ese derecho fundamental como posibilitador del pleno desarrollo de una persona.

\section{Artículo 13}

1. Los Estados Partes en el presente Pacto reconocen el derecho de toda persona a la educación. Convienen en que la educación debe orientarse hacia el pleno desarrollo de la personalidad humana y del sentido de su dignidad, y debe fortalecer el respeto por los derechos humanos y las libertades fundamentales. Convienen asimismo en que la educación debe capacitar a todas las personas para participar efectivamente en una sociedad libre, favorecer la comprensión, la tolerancia y la amistad entre todas las naciones y entre todos los grupos raciales, étnicos o religiosos, y promover las actividades de las Naciones Unidas en pro del mantenimiento de la paz (PIDESC 2020).

Ahora bien, como corolario de lo anterior, debemos señalar que una constante entre los derechos señalados en la segunda Carta norteamericana y nuestro texto Constitucional es que a pesar de tener un sentido propositivo y conciliador con la persona y su dignidad, ambos instrumentos se mantienen alejados de señalar el cómo habrán de cumplirse tal altos fines, hecho que nos debe poner a considerar seriamente que a veces no solo bastan las buenas intenciones insertas en las leyes, sino que éstas deben ser lo suficientemente claras y directas para no dejar lugar a la especulación y sobre todo para evitar que no puedan ser cumplidos tal altos objetivos en pro de la dignidad de las personas en cualquier lugar del orbe.

\section{CONCLUSIONES}

Los derechos sociales son, sin lugar a duda, derechos fundamentales que deben ser protegidos, pues inciden en los aspectos más sensibles de la dignidad de las personas.

La segunda Carta de derechos de los Estados Unidos es un instrumento de gran calado que, por no estar inserta en el texto constitucional, lamentablemente se encuentra supeditada a las decisiones de los jueces de la Corte Suprema, pues su aplicación depende de procesos de interpretación y hoy en día, este alto tribunal norteamericano sigue una tendencia ultraconservadora, donde la premisa radica en la interpretación casi literal del texto constitucional. Aunado a lo anterior, el hecho de que los Estados Unidos no sean parte del Pidesc, aleja la posibilidad de lograr el pleno reconocimiento de los derechos sociales en aquella nación.

En el caso mexicano, no hay duda que nuestra Constitución, desde su nacimiento en el año de 1917 , tuvo todo un sesgo social, que a lo largo del tiempo se ha venido reforzando, sin embargo, el gran problema que nos aqueja es que mucho del texto constitucional se torna hueco, pues en la práctica no logran hacerse efectivos los derechos sociales, afectando principalmente al sector vulnerable de nuestra población. En este sentido, podemos afirmar que una de las razones para llegar a tal conclusión tiene que ver con la falta de claridad en la expresión de nuestras leyes, pues en la mayoría de los casos no se señala cómo habrá de lograrse la materialización de dichos derechos sociales, aunado esto la frecuente falta de recursos económicos que limitan la actuación gubernamental para cumplir con sus obligaciones en la defensa de la dignidad de la persona. 


\section{BIBLIOGRAFÍA}

- CPEUM. Constitución Política de los Estados Unidos Mexicanos. (2020). Recuperado 04 de febrero de 2020 de https://n9.cl/c8ta9.

- Constitución francesa. . 4 de noviembre de 1848. Recuperada el 26 de agosto de 2019 de https://n9.cl/2bl72.

- Fabra Zamora, J. L. (ed). (2015). Enciclopedia de Filosofía y Teoría del Derecho, Volumen dos. México: Instituto de Investigaciones Jurídicas de la UNAM.

- García Pérez, M. (2013). El silencio administrativo en España. Revista Misión Jurídica, (6): 57 - 83. DOI: https://doi. org/10.25058/1794600X.62

- Gaxiola Moraila, F. J. (2004). Enciclopedia Jurídica Mexicana, 2a ed. México: Porrúa-Unam.

- Kennedy, D. (1999) Freedom for free. The american people in depression and war 1929-1945. Nueva York: Oxford University
Press.

- PIDESC, Pacto Internacional de Derechos Económicos, Sociales y Culturales. (2020). Recuperado 04 de marzo de 2020 de https://n9.cl/51ajs.

- Pisarello, G. (2007). Los Derechos sociales y sus garantías. Trotta: Madrid.

- Sustein, C. (2018). Las cuentas pendientes del sueño americano. Buenos Aires: Siglo XXI Editores.

- National Archives. United States Of America. 2019. Recuperado 04 de marzo de 2020 de https://n9.cl/n2v11.

- Organización Internacional del Trabajo (OIT). Seguridad Social. Recuperado 03 de marzo de 2020 de https://n9.cl/f5ya1.

- Schapire, A. (2018). El discreto sistema conservador que conquistó la Corte Suprema de EEUU. 5 de septiembre de 2018. Recuperado 02 de marzo de 2020 de https://n9.cl/2ufb3. 